ALPHA Nº 28 Julio 2009 (197-207)

ISSN 0716-4254

http://alpha.ulagos.cl

\title{
DE LECTOR-ESPECTADOR A COPARTÍCIPE: EL PAPEL DEL PÚBLICO EN LAS PULGAS DRAMÁTICAS DE JOSÉ MORENO ARENAS
}

From reader-spectator to active participant: The role of the audience in José Moreno Arenas’s Dramatic Snippets

John P. Gabriele*

"I regard the theatre as the greatest of all art forms, the most immediate way in which a human being can share with another the sense of what it is to be a human being”. ["Considero el teatro la forma más grande del arte, la manera más inmediata en que un ser humano puede compartir con otro ser humano la sensación de lo que es ser humano"].

Oscar Wilde

Los medios de comunicación se han aprovechado siempre de la innata contextura dramática de los acontecimientos de la vida diaria. Los inicios de los telediarios y los titulares de los periódicos se empeñan en picar la curiosidad de sus espectadores y lectores y estimular su interés con declaraciones como las siguientes: "El atentado más grave en tres décadas causa medio centenar de muertes”; “Muere apuñalada una joven de 25 años”; "La crisis económica recrudece y golpea al país" y "Lluvias torrenciales con graves consecuencias". Enganchados y seducidos por cortos enunciados sensacionalistas y sin más contexto que la propia realidad inmediata, los espectadores y lectores se imaginan de inmediato las escenas adelantadas en tales flashes noticiarios.

Las piezas cortas del dramaturgo granadino José Moreno Arenas (Albolote, 1954) también enganchan y seducen. También constituyen flashes dramáticos. Moreno Arenas escribe un teatro más bien alusivo y evocador que manifiesto y explícito. Maestro irrebatible de la síntesis estructural y contextual, estimula la conciencia social y artística de sus lectores-espectadores mediante un mínimo de palabras y situaciones empinadamente sugestivas. Como se ha de esperar en un mundo siempre más tecnificado en que la satisfacción inmediata es la norma y no la excepción, el teatro de Moreno Arenas da gratificación instantánea con el fin de revolver la conciencia de los lectores-espectadores e instigar su participación activa en el acto teatral. De 
John P. Gabriele

los más de setenta textos dramáticos que ha escrito, en ninguno es más evidente la destreza y técnica de Moreno Arenas por asentar una forma y un fondo teatral mediante una concisión textual y contextual como en las piezas incluidas en la colección titulada Teatro mínimo (Pulgas dramáticas), que consta de veinte textos, todos de una sola página menos la última que apenas llega a dos páginas y media.

Basicamente, el teatro es el arte de representar obras dramáticas. También hay que recordar que el término "drama” viene de la palabra griega que significa "hacer" y se asocia normalmente con la puesta en escena de una historia que narra la vida de individuos en que hay conflicto, tensión, oposición y emoción. Es, esencialmente, un arte cuyo "efecto final" es el resultado - como dice Martin Esslin- "de un equilibrio delicado de una multitud de distintos elementos y la interacción de éstos” (1979:53).

Las pulgas dramáticas de Moreno Arenas son todo lo contrario de lo que se entiende tradicionalmente por teatro, ya que no hay la "multitud" de elementos a que se refiere Esslin. El escenario carece de decoración. Todo lo que ocurre está contenido en una sola didascalia. La acción no es representada per se; consiste en una aparición en escena, fugaz y silenciosa, de personajes que nos recuerda a la pantomima. Los personajes -identificados genéricamente (actor, actriz, espectador, paisano, policía, hombre, mujer, ella, él, exhibicionista, periodista, etc.) — así como los objetos o animales que protagonizan las obras no hablan ni dialogan. Por lo mismo, es difícil hablar de equilibrio e interacción de elementos cuando se trata de una escasez de estos mismos. Sin embargo, hay teatro y hay drama.

El de Moreno Arenas es un teatro inconformista y sus pulgas dramáticas no son excepciones. Como todo teatro de la época posmoderna, las suyas son piezas que "niegan la existencia de reglas y reglamentos que gobiernan el diálogo, el personaje y la estructura dramática” (Pavis, 1992:59). Como todo autor posmoderno, Moreno Arenas reinventa la teoría de la expresión estética oponiéndose a las normas establecidas, pero no abandona las esencias encapsuladas en ellas. Sus pulgas dramáticas no son obras que se puedan juzgar de acuerdo con las categorías y expectativas tradicionales; son textos que buscan nuevas reglas y nuevas categorías y que obedecen a distintas expectativas. Son piezas intencionadamente subversivas y transgresivas, en el mejor sentido de los términos. Se trata de un teatro que deriva su razón de ser y de hacer artístico de la contestación de las prácticas tradicionales y de la participación del lector-espectador en el propio acto creativo.

\section{LOS TÍTULOS}

Idear un título para una obra es el arte de sintetizar y seducir por excelencia. El título tiene como objetivo principal dar sentido a la obra. 
Constituye el primer contacto del lector o espectador con el texto. El significado del título está, de alguna manera u otra, entretejido a lo largo de todo el texto. Por escueto o complejo que sea, el título esconde mensajes de gran alcance temático e ideológico. Se trata de una inscripción enigmática que oculta mensajes políticos, sociales, filosóficos o artísticos que se aclaran sólo después de leer o de ver la obra. El título es la invitación que ofrece Moreno Arenas a su público para que entre en su obra en busca del mensaje escondido. Todo título es axiomático pero, también, sugestivo, por no decir tentador. Es el primer desafío de interpretación a que se enfrenta el lector o el espectador.

Los títulos de las pulgas dramáticas de Moreno Arenas son extremadamente sucintos y precisos: La gata, La escoba, El tropezón, Las gafas, El rifirrafe, La agenda, La televisión, El payaso, La propina, La cantante, El tren, La crusanta, etc. Son títulos muy "sugerentes" que "indican quiénes son los auténticos protagonistas", como ha observado Marie-Claire Romero, y en los cuales "el contenido se halla implícito" (2007:7). Si bien es verdad que los títulos constituyen un vislumbre a priori de lo que pasa en las obras y de quienes o que las protagonizan, también es el primer paso que da el dramaturgo para despabilar la curiosidad del lector-espectador y avivar su potencial creativo. Es la primera oportunidad que le brinda a sus lectoresespectadores para asumir el papel de copartícipe en la construcción del hecho teatral. Dicho de otro modo, el título pone en marcha la seducción artística del receptor; la invitación a interactuar con el texto, de iniciar lo que Richard Murphy ha llamado "el procedimiento esencial e indispensable de interacción entre lector y texto que es tan fundamental y necesario para llegar al significado último de la obra” (1999:295). Como todo autor posmoderno, Moreno Arenas exige que el lector-espectador no se quede en el margen. Se empeña en que su público se involucre desde el primer contacto con sus pulgas dramáticas.

En el momento cuando el lector-espectador se enfrenta a cualquiera de los títulos, se le incita y se le provoca, inmediatamente, la imaginación. Empieza a imaginarse escenas, consciente o inconscientemente; a conjeturarse imágenes que toman como punto de partida lo asociado con, o lo inferido por el título. El gato, por ejemplo, es una especie conocida por su independencia. Son símbolos de meditación, misterio y sabiduría. Son animales astutos, hábiles, listos, intuitivos y vigilantes. Según la cultura, donde viva uno, el gato negro da mala suerte. Las gafas se asocian más que nada con la vista, específicamente, con la corrección de la vista; el rifirrafe con una discusión ruidosa, pero sin importancia duradera o trascendental; la escoba con el acto barrer; la agenda con los quehaceres diarios y la televisión con los medios de comunicación en directo, la transmisión de información y noticias, de progra- 
John P. Gabriele

mas basados en la realidad y de programas de diversión. El payaso es un personaje representado comúnmente con vestimentas extravagantes, maquillaje excesivo y pelucas llamativas. Generalmente, al payaso se le asocia con un artista de circo cuya función es hacer reír a la gente, gastar bromas y hacer trucos divertidos. El tren, siendo un medio de transporte locomotor, nos hace pensar en el viaje, la circulación y el movimiento. O sea, el espectador o lector se enfrenta a las pulgas dramáticas de Moreno Arenas con nociones preconcebidas. El marco escénico textual, contextual y temático se establece, ya, antes de dar inicio a la acción.

Los títulos de Moreno Arenas sirven para orientar visual y metafóricamente al lector-espectador sugiriendo que aquello que se va a representar va enmarcado por elementos reconocibles. Dan la impresión inicial de referirse a contextos o temas conocidos. En La gata, por ejemplo, "aparece una gatita de pelo negro" que se roza contra "una torre inexpugnable”. Al desplomarse la torre, se revela "el cadáver de un hombre". "Provocadora e ingenua", la gata abandona el escenario y, a punto de salir, "su sombra se proyecta sobre el fondo, semejando la negra silueta de una mujer” (2003:37).

La imagen provocadora e ingenua de la gata coincide con la imagen preconcebida del espectador. Pero la torre supuestamente impenetrable que se convierte en hombre muerto al caerse y la gata que se convierte en mujer nos dirigen hacia otros contextos inicialmente impensados como las imágenes de Adán y Eva y el derrumbamiento de las Torres Gemelas. Al contraponer un contexto lógico sugerido por el título y un contexto imprevisto pero igualmente lógico, Moreno Arenas crea un efecto desestabilizador para recordarnos, como asevera Arnold Aronson, que "el diseño posmoderno es un recordatorio disonante que no hay un solo punto de vista que puede predominar, aun cuando se trata de una sola imagen sencilla" (1991:2). Por un lado, lo que transcurre en la pieza coincide con lo prefigurado por el lectorespectador creando un intertexto entre lo expuesto en la pieza y su conocimiento del contexto inferido. Por otro, choca con lo que pre-suponía el lector-espectador creando cierta inquietud de conciencia. Hay una fusión de texto y contexto en un nivel, y un desajuste en otro lo cual nos da a entender que la realidad es una noción fundamentalmente ambivalente que no precede el texto sino que es el producto del texto en relación con la intuición y con la sensatez del lector-espectador.

La contraposición de lo que anticipa el lector-espectador y lo que pasa en la pieza involucra al público eficaz y certeramente y asegura que aquello que presencia es puro teatro, puro drama. Si la sorpresa y lo inesperado son dos de los elementos indispensables de toda actividad dramática, como afirma Bernard Beckerman (1970:145-57), lo que alcanza Moreno Arenas, en tan 
sólo una página, es indiscutiblemente teatro e indisputablemente drama. Sirva un ejemplo más para subrayar lo susodicho.

En El payaso, como en todas las piezas de la colección, "el escenario carece de decoración”. Así, nos enfrentamos al texto con imágenes preconcebidas referentes a la figura de un payaso. La acción comienza cuando "por uno de los laterales asoma un ESPECTADOR”. Este lleva una silla que deja en el suelo. Se sienta. "Por el lateral opuesto un PAYASO hace una aparición circense”. Al ver al payaso, el Espectador sufre un ataque de risa. Tras revolcarse por el suelo, el Espectador se pone de pie. El Payaso, "herido en su dignidad”, (67) saca una pistola y dispara al Espectador, que muere. El Payaso "se vuelve hacia el público y se dispone a hacer su número" (67). Leemos que los "espectadores lloran a lágrima viva” (67). De nuevo, se contraponen lo adelantado por el título, lo anticipado por el lector-espectador, y lo inesperado de la acción para crear una obra cuyo texto y contexto se funden y se separan al mismo tiempo. Como todas las pulgas dramáticas de Moreno Arenas, El payaso es un drama proteico y juguetón, una pieza fundada en el intercambio entre la concepción, la percepción y la recepción. David George diría que la pieza se funda en y capta la ambigüedad e incertidumbre de la condición humana posmoderna (1989:82-83). El payaso termina, precaria e irresolublemente, entre el patetismo y la alegría igual que sus lectores-espectadores. Nunca se sabrá con certeza si "algunos espectadores lloran a lágrima viva" (67) por reírse de lo que acaban de presenciar o por sentir tristeza.

\section{LAS DIDASCALIAS}

Adelardo Méndez Moya, hablando del teatro de José Moreno Arenas, escribe que "en síntesis, se trata de un teatro que busca la respuesta inmediata. Pretende ser el estímulo, el chispazo, que desencadena la reacción del receptor. Así, este teatro se verifica en clave de brevedad" (2000:10). Pues bien, donde mejor se aprecia la destreza inimitable de Moreno Arenas por la brevedad y concisión estructural en que hace hincapié Méndez Moya es en las didascalias. Las acotaciones escénicas suelen ser, como bien se sabe, partes del texto teatral. En su función más elemental sirven para situar la acción, especificar el decorado y describir las acciones de los personajes y la interacción entre ellos. Pero en las pulgas dramáticas, las didascalias constituyen la propia acción de las piezas, una afrenta mayor por parte del dramaturgo a los códigos convencionales.

La falta de acción tradicional y el uso de acotaciones para sustituir a la acción reflejan la perspectiva desconstructivista de Moreno Arenas por romper con la jerarquía estructural convencional del hecho teatral en la cual la acción ocupa un puesto de privilegio. Si la acción es el sine qua non del teatro 
John P. Gabriele

que los otros elementos complementan de distintas maneras —mediante las cuales el dramaturgo asiente su mensaje- las pulgas dramáticas de Moreno Arenas demuestran que rebelarse contra el canon no resulta en un teatro menos artísticamente comprometido y dinámico.

En La noticia, los personajes son un periodista y un viandante. El Periodista llora "a moco tendido". Está desesperado porque el periódico tiene "todas las páginas en blanco". Cuando aparece el Viandante, el Periodista le ofrece una pistola y un fajo de billetes. El Viandante rechaza la oferta, pero el Periodista insiste. Le ofrece la pistola y dos fajos de billetes. El Viandante sigue desinteresado. Cuando aquél le ofrece la pistola y tres fajos de billetes, el Viandante acepta. Guarda el dinero pero "muy a su pesar". Luego se pega un tiro y muere. Leemos que "el PERIODISTA es feliz". Antes de caer el telón, “enseña su periódico al público” (41). Ya hay noticia.

El único personaje de El móvil es un actor. Dice la didascalia: “Aparece un ACTOR, que se dirige al centro del escenario. Cuando va a iniciar la interpretación de un monólogo, suena su móvil”. El Actor contesta, mantiene una conversación y luego cuelga. Vuelve a dar inicio a su monólogo y el móvil vuelve a sonar. Contesta "muy enfadado". Después de un breve diálogo, "estrella el móvil contra el suelo". Al iniciar de nuevo su monólogo, suena el móvil de un espectador. "Derrumbado", el Actor llora. De repente, suenan varios móviles. Pronto el teatro se inunda de "un concierto de música de móviles” (57). El Actor, desconsolado, sale del escenario llorando mientras cae el telón.

En otra pieza, “aparece un EXHIBICIONISTA”, personaje que da el título del texto. Se detiene en el centro del escenario. Después de sonreir abre "la gabardina de par en par". Al caminar una mujer por el escenario, el Exhibicionista "la encara y abre la gabardina". Tras "dedicarle todo tipo de improperios”, la Mujer sale y el Exhibicionista gira hacia el público, sonríe picaronamente y abre la gabardina. Según la acotación escénica, "Viste un elegante traje, con camisa y corbata de seda” (61).

La noticia, El móvil y El exhibicionista son piezas en las cuales Moreno Arenas demuestra su característica habilidad para escribir un teatro taciturno y sigiloso, carente de interacción verbal entre los personajes y cuya acción se reduce a la descripción de un solo y repetido movimiento de los personajes. No se trata de una serie de distintas acciones interconectadas y complementadas por lo que se expone en las acotaciones escénicas. En las pulgas dramáticas, las didascalias no describen la acción, no la contextualizan, sino que la generan. El cuadro estático tradicionalmente creado por la didascalia, que suele complementar y contextualizar la acción y ambientar la situación, es la única acción de la pieza. Un solo elemento teatral cumple dos propósitos. Las tres piezas dependen más de la introspección y de la curiosidad del 
público que de la bravuconería y actuación de los actores. Ha de notarse que Moreno Arenas no descarta la función primordial de la acción dentro del hecho teatral sino que la baja de su rango supuestamente privilegiado para convertirla, en palabras de Douwe Fokkema, en un acto de "connotaciones semánticas” (1997:38). Lo verbal cede a lo visual, la exteriorización de la acción deja paso a la interiorización de lo representado pero lo teatral y lo dramático perduran. La condición aminorada de la acción y el papel enaltecido de las didascalias en combinación con títulos que despiertan, efectivamente, la conciencia artística y social del lector-espectador logran ofuscar las distinciones incontestadas de la expresión teatral canónica y subrayar el fervor posmoderno de desafiar todo paradigma artístico autoritario.

\section{LOS PERSONAJES}

Los personajes de estas pulgas dramáticas se integran perfectamente en el sistema semántico que crea el dramaturgo. Son seres que carecen de identidad propia en el sentido estricto de la palabra. Se identifican por su género, por su profesión o por su rango social. Sin embargo, son más que estereotipos. En los personajes de Moreno Arenas, los lectores-espectadores se ven reflejados en el contexto de una gran gama de personalidades, emociones, entornos sociales, políticos, familiares y culturales, aficiones, ambiciones, vínculos personales, temores y preocupaciones, etc. Los de Moreno Arenas son metapersonajes, personajes que trascienden una alusión velada o un vínculo superficial y efímero con lo real. Los personajes de Moreno Arenas somos sus lectores y espectadores; y los enredos, tinglados y embrollos emocionales, sociales, políticos, familiares, etc. de sus personajes son nuestros enredos, tinglados y embrollos.

José Luis Alonso de Santos afirma que "el personaje es una carga emocional que se dispara en una u otra dirección, de forma más intensa y directa (por su síntesis) que las personas en la vida real” (1998:289). "Ser capaces de hacer visible en ellos esa carga emocional es una de las necesidades del escritor” (290). José Moreno Arenas cumple al pie de la letra lo que afirma de Santos y lo hace en un espacio y en un tiempo infinitamente reducidos. El escenario carece de decorado porque se ambienta por nuestra realidad. No hay acción propia porque la acción depende del lector-espectador y se pone en marcha sólo en el momento cuando éste se ve reflejado en y ve reflejado su entorno en el escenario que idea el dramaturgo. Todo lo que necesita Moreno Arenas para hacer teatro se encuentra en su público. Lo único que hace es empeñarse en engancharnos y trasladarnos, metafórica- 
John P. Gabriele

mente hablando, a un escenario desprovisto de arreglo y de adornos para hacernos conscientes de la innata teatralidad de la vida.

El personaje de El progreso, por ejemplo, es un solo hombre. Cuando suena el despertador, "el HOMBRE que dormía, salta de inmediato". Se lava, desayuna, se viste, se peina y sale del escenario frenéticamente. Vuelve sin aliento, "recoge una cartera de enormes dimensiones" que se había olvidado y sale de nuevo. Regresa otra vez. "Come, ojea unos papeles, se desviste y se acuesta”, con una prisa igualmente delirante. Mientras el escenario se inunda de un "silencio inquietante", suena el despertador. La imagen final es del "HOMBRE inerte" en el suelo. Cae el telón, pero el despertador "no deja de sonar" (45). En tanto, el personaje de Las antípodas es un solo actor que aparece en escena "andando con las manos". Se detiene en el centro del escenario y mira al público. "Contrariado, se pone de pie”. Hace gestos de desaprobación y de no entender el comportamiento del público. Hace una mueca de desprecio; se apoya de nuevo en sus manos y sale del escenario. Al final de la didascalia, Moreno Arenas escribe que "Cae el telón. ¡Perdón... ! Sube el telón” (55). ¿A quién no se le ocurre en ese momento la famosa frase que pronuncia Jaime en Como gustéis de Shakespeare? "El mundo entero es un escenario, y todos los hombres y mujeres, simplemente, actores” (1942: 225). Para Shakespeare era una metáfora; para Moreno Arenas y sus lectoresespectadores es una realidad.

Francisco Morales Lomas ha escrito que los dramas de José Moreno Arenas "producen una intensidad perversa y actúan como un estilete o punzón en el pensamiento del lector-espectador" (2000:6). Es, precisamente, mediante sus personajes que Moreno Arenas logra la condensación y el ímpetu dramático a que alude Morales Lomas.

El Hombre de El progreso y el Actor de Las antípodas, como los personajes de las otras piezas aquí discutidas y todos los personajes de las pulgas dramáticas son la base del discurso del dramaturgo. El Hombre de El progreso y el Actor de Las antípodas no son personas específicas identificables en el contexto del hecho teatral, o sea dentro de los confines del escenario propio, pero sí en el contexto de la realidad del público, ya que representan a toda persona, a todo individuo, a todos los lectores-espectadores de Moreno Arenas que se identifican con ellos, que son muchos. Se trata de un personaje “pluralista” por excelencia (Bertens, 1987:141). El teatro de Moreno Arenas carece de personajes individuales e identificables por nombres porque son réplicas de seres de la realidad objetiva más inmediata, esa realidad que es la fuente desde donde Moreno Arenas extrae personajes para situarlos en el escenario. En cuanto a los personajes de Moreno Arenas, la otredad —un concepto tan fervientemente debatido en el arte moderno en general- se 
encuentra entre su público no en el escenario. Paralelamente, la otredad del público se encuentra en los personajes del dramaturgo.

El espectador sin abandonar las butacas o los palcos del teatro y el lector su sillón de lectura, se traslada al escenario como el personaje inferido mediante la metalepsis, técnica utilizada para explorar la relación entre lo ficticio y lo real y dramatizar la frontera siempre más frágil entre la ficción y la realidad y entre vivir el papel y desempeñar el papel (Malina, 2002:2-8). No hay distinción entre los personajes teatrales de Moreno Arenas y los personajes de la realidad inmediata. Ellos y nosotros, que vienen a ser lo mismo, ocupamos ambos mundos, simultáneamente. La cuarta pared ha quedado efectivamente derrumbada. El dilema ontológico se profundiza.

\section{A MODO DE CONCLUSIONES}

Como otros dramaturgos modernos, José Moreno Arenas se motiva por asentar, en sus pulgas dramáticas, una visión del mundo como realidad relativa e inestable; una visión impulsada por ideas filosóficas y artísticas no convencionales que desafían el absolutismo inviolable de los modos tradicionales de la representación teatral. Pienso, por ejemplo, en Manuel Tamayo y Baus, Ramón del Valle-Inclán, Miguel de Unamuno, Federico García Lorca, Carlos Arniches, Ramón Gómez de la Serna, Jacinto Grau, Rafael Alberti, Antonio Martínez Ballesteros, Manuel Martínez Mediero, Jerónimo López Mozo, Alfonso Vallejo, Luis Araújo, Laila Ripoll, Juan Mayorga, Àngels Aymar, Itziar Pascual, Paco Bezerra y muchísimos más. Si bien es verdad que estos dramaturgos renuncian el dogmático teatro convencional en cuanto a forma y fondo, también, invitan y requieren "la valiosa colaboración del público" (La televisión 53), para citar al propio Moreno Arenas. Demandan la colaboración de los lectores-espectadores durante la función y, también, después. Lo mismo ocurre en las pulgas dramáticas.

$\mathrm{Al}$ caer el telón al final de las pulgas dramáticas, no se pone fin a la representación artística, a la presentación de la vida teatralizada. No es ese el momento cuando se restituye la cuarta pared divisoria, la frontera que divide realidad e ilusión. Es todo lo contrario. La confluencia dinámica de realidad e ilusión se profundiza para hacer hincapié en la innata e irrefutable condición teatral de la vida y la igualmente inherente e innegable cualidad realista del teatro.

El teatro es el género en el que se alcanza, más completa y efectivamente, la simbiosis entre realidad y ficción, entre vida y arte, entre verdad y mentira. Las pulgas dramáticas de Moreno Arenas responden fundamental y tajantemente a este propósito. A pesar de su brevedad textual, hay planteamiento de conflicto, nudo, desenlace, verosimilitud, catarsis, causalidad, 
John P. Gabriele

causa y efecto, etc. Hay todo lo que se espera de una obra teatral más larga porque las pulgas dramáticas de José Moreno Arenas son flashes penetrantes de la realidad en sus aspectos más elementales, esenciales y reveladores.

\author{
The College of Wooster* \\ Department of Spanish \\ Wooster, OH 44691 (U.S.A.) \\ jgabriele@wooster.edu
}

\title{
BIBLIOGRAFÍA
}

ALONSO DE SANTOS, José Luis. La escritura dramática. Madrid: Castalia, 1998.

ARONSON, Arnold. "Postmodern Design", en Theatre Journal 43.1 (1991):1-13.

BECKERMAN, Bernard. Dynamics of Drama. Theory and Method of Analysis. New York: Alfred A. Knopf, 1970.

BERTENS, Hans. "Postmodern Characterization and the Intrusion of Language”, en Exploring Postmodernism. Ed. Douwe Fokkema y Matei Calinescu. Amsterdam: John Benjamins (1987):139-159.

ESSLIN, Martin. An Anatomy of Drama. New York: Hill and Wang, 1979.

FOKKEMA, Douwe. "The Semiotics of Literary Postmodernism", en International Postmodernism: Theory and Literary Practice. Ed. Hans Bertens y Douwe Fokkema. Amsterdam: John Benjamins (1997):15-42.

GEORGE, David. "On Ambiguity: Towards Post-Modern Performance Theory”, en Theatre Research International 14.1 (1989):71-85.

MALINA, Debra. Breaking the Frame: Metalepsis and the Construction of the Subject. Columbus: Ohio State UP, 2002.

MÉNDEZ MOYA, Adelardo. "El teatro de José Moreno Arenas: una dramaturgia de la concisión”, en Teatro indigesto. De José Moreno Arenas. Madrid: Fundamentos (2000):9-20.

MORALES LOMAS, Francisco. "Teatro contemporáneo”, en Diario de Málaga, 12 de noviembre de 2000, Papel literario: 6-7.

MORENO ARENAS, José. Teatro mínimo (Pulgas dramáticas). Granada: Dauro, 2003.

MURPHY, Richard. Theorizing the Avant-Garde. Modernism, Expressionism, and the Problem of Postmodernity. Cambridge: Cambridge UP, 1999.

PAVIS, Patrice. Theatre at the Crossroads of Culture. Trad. Loren Kruger. London: Routledge, 1992. 
ROMERO, Marie-Claire. "El silencio de la palabra”, en Teatro mínimo (Pulgas dramáticas), de José Moreno Arenas. Granada: Dauro (2007): 7-10.

SHAKESPEARE, William. "As You Like It". The Complete Plays and Poems of William Shakespeare. Edición e Introducción. William A. Neilson y Charles J. Hill. Boston: Houghton, Mifflin (1942):211-243. 